DOI: $10.12731 / 2658-4034-2020-5-57-66$

УДК 378.14

\title{
РАЗВИТИЕ ИНЖЕНЕРНОГО ОБРАЗОВАНИЯ В СССР С 1917 ПО 1945 ГОДЫ (ИСТОРИЧЕСКИЙ АСПЕКТ)
}

Ероченко А.В., Трофимова Л.Н.

Успешное развитие экономики любой страны зависит от качества образования, поэтому одной из приоритетных проблем для России является повышение качества инженерного образования.

Проведение исследования становления и развития инженерного образования в России позволяет выявить сильные стороны каждого периода развития высшей школь, что в результате поможет повысить качество инженерного образования. В данной статье рассматривается развитие высшего инженерного образования 8 СССР на период от революиии 1917 года по 1945.

Револючия и последующая гражданская война приостановила развитие инженерного дела в начале данного периода, что обусловлено эмиграцией высококвалифищчированных инженеров и студентов инженерно-технических вузов за гранииу. В результате политических изменений происходило привлечение рабочих и крестьян для обучения в высшей технической школе. Как следствие этого, улучшилось качество школьного образования по естественным дисциплинам, так как подготовка высококвалифищированных инженерных кадров в вузах неотделима от школьной подготовки по математике, физике, химии. В вузах большое внимание уделялось практическим занятиям, 6 учебные планы была введена производственная практика. Профессия инженера была престижной и востребованной в России.

Анализ полученных результатов показал, что ччель, характер обучения и образования всегда зависят от ичелей и задач, стоящих перед государством на данном этапе и государственной образовательной политики. Реформирование инженерного образования из-за идеологических мотивов сдерживало развитие. 
Ключевые слова: инженерное образование; история образования в России; практический характер образования; высшее техническое образование.

\section{FORMATION OF ENGINEERING EDUCATION IN RUSSIA AFTER REVOLUTION OF 1917-1945 YEAR}

\section{Eroshenko A.V., Trofimova L.N.}

The successful development of the economy of any country depends on the quality of education, therefore, one of the priority problems for Russia is to improve the quality of engineering education.

Research into the formation and development of engineering education in Russia allows us to identify the strengths of each period of development of higher education, which, as a result, will help improve the quality of engineering education. This article examines the system of higher engineering education in Russia for the period from the 1917 revolution to the outbreak of World War II.

The revolution and the ensuing civil war suspended the development of engineering at the beginning of this period, which was due to the emigration of highly qualified engineers and students of engineering and technical universities abroad. As a result of political changes, workers and peasants were attracted to study at a higher technical school. As a consequence, it improved the quality of school education in the natural sciences as well as the training of highly qualified engineering staff in universities is inseparable from the school training in mathematics, physics, chemistry. In universities, much attention was paid to practical training, industrial practice was introduced into the curriculum. The engineering profession was prestigious and in demand in Russia.

The analysis of the results obtained showed that the goal, nature of training and education always depend on the goals and objectives facing the state at this stage and the state educational policy. The reform of engineering education, due to ideological motives, held back development.

Keywords: engineering education; history of education in Russia; practical nature of education; higher technical education. 
Для экономического развития России особенно важным всегда являлось инженерное образование. Подготовка высококвалифицированных инженеров во многом зависит «от степени обоснованности трех основных узлов учебного процесса: цели обучения (для чего учить?), его содержания (чему учить?) и принципов организации учебного процесса (как учить?)» [10].

Первостепенное значение имеет цель обучения. В дальнейшем на основе поставленной цели составляется содержание, определяются методы и средства обучения. Психологи и педагоги-исследователи А.С. Макаренко, Б.П. Есипов, Н.Ф. Талызина, И.И. Ильясов в своих работах определяют цель как ожидаемый конкретный результат учебно-воспитательного процесса.

С момента зарождения высшего инженерного образования в России вопрос постановки цели обучения был актуальным. Проведенное исследование показывает, как менялись цели и содержание обучения с изменением социально-экономического, политического развития России в период после революции 1917 года до начала Второй мировой войны. Актуальность данного исследования обусловлена потребностью повышения качества высшего инженерного образования. Для этого необходимо использовать наиболее ценные достижения отечественной педагогической науки.

В конце XIX в. Российская Империя практически не уступала по качеству подготовки инженеров ни одной стране мира. Известным во всём мире считался «русский метод подготовки инженеров» $[4,11]$. В начале $\mathrm{XX}$ века в подготовке инженеров главную роль играют политехнические институты, совмещающие множество направлений подготовки. Идет активное развитие негосударственной высшей школы, увеличение и расширение контингента обучающихся.

Такая тенденция развития инженерного образования сохранялась до 1917 года. Однако, под влиянием революции и последующей гражданской войны, значительная часть высококвалифицированных инженеров и студентов инженерно-техни- 
ческих вузов эмигрировало за границу, тем самым затормозив развитие инженерного дела.

Необходимо было заново создать систему инженерного образования.

Руководство страны понимало, что руководить предприятиями должны были специалисты знающие производство, однако таковых катастрофически не хватало. Рабочие-выдвиженцы не обладали профессиональными знаниями, более того имели общую подготовку на уровне начальной школы. Поэтому в 1919 году по решению правительства создаются рабочие факультеты. Основной задачей рабфаков стало широкое вовлечение рабочих и крестьян в подготовку для обучения в высшей технической школе. К концу 1920 года на рабфаке Московского университета рабочие составляли 34\% слушателей, крестьяне $-56 \%$.

В 1921 году Совет народных комиссаров утверждает «Положение о высших учебных заведениях РСФСР», которым были определены цели и задачи высшей школы:

- создать кадры специалистов по различным отраслям РСФСР;

- готовить научных работников для работы в научных, научнопроизводственных учреждениях;

- распространять научные знания среди рабочих и крестьян [3]

В 1931 году возникает необходимость реконструкции старых предприятий, строительства новых, отвечающих современным требованиям. Правительство перед техническими науками ставит новые еще более ответственные задачи: вся страна должна включиться в освоение новой техники. Гражданам необходимо стать высококвалифицированными специалистами, активно повышать технические знания [8].

Для стимулирования рабочих и инженеров в освоении новой техники, в 1933 году повсеместно на заводах вводится технический экзамен. По данным газеты «Правда» от 18 декабря 1933 года, экзамен прошел на 30 предприятиях, в нем приняло участие 50294 человека (58,5\% от всей рабочей молодежи) и только 3272 человека (6,5\% от числа участников) сдали экзамен на оценку «неудовлетворительно». 
В тридцатые годы правительство уделяет большое внимание улучшению жилищных условий инженеров, занятых непосредственно на производстве. Инженеры получили право на дополнительную площадь. В 1932 году издано особое постановление СНК СССР о постройке 102 домов для инженерных специалистов. Средняя зарплата инженера с 1930 по 1933 годы выросла на 44,6\%. В 1933 году 58\% инженеров смогли получить санаторно-курортное лечение. Особое внимание уделялось развитию пригородных хозяйств, основной целью которых было обеспечение мясом, овощами инженерно-технических работников [8].

К 1933 году была упразднена большая часть нововведений, внесенных правительством в учебные планы, и учебные заведения вернулись к дореволюционным порядкам. В результате начало стремительно улучшаться качество преподавания в средних школах, особенно это коснулось естественных наук и математики. К концу тридцатых годов уровень требований по математике к ученикам средних школ приблизился к высокому дореволюционному стандарту. В то же время технические институты исключили специальные привилегии для детей рабочих и крестьян и снова ввели отбор студентов по способностям. Профессия инженера продолжала быть популярной в России, и технические учебные заведения снова стали привлекать внимание лучших учеников [9].

В 1934 году между Академией наук и Всесоюзным советом научных инженерно-технических обществ был заключен договор. Суть этого договора:

- Академия наук не реже одного раза в квартал обязуется делать сообщения о своих законченных работах;

- совет инженерно-технических обществ обязуется пропагандировать достижения в науке, способствовать внедрению научных работ в промышленность;

- совместная организация и проведение конференций, диспутов для популяризации технических знаний [7].

К концу тридцатых годов преподавание на инженерных специальностях опять становится темой для оживленных дискуссий. По 
мнению М. Е. Грицевского существует излишнее дробление специальностей. Так, например, существуют специальности «вагонное хозяйство» и «паровозное хозяйство». М.Е. Грицевский сравнил учебные планы и выяснил, что паровозники не изучают вагоны, а вагонники - паровозы. При этом в своей практической деятельности инженерам этих двух специальностей приходится иметь дело с вопросами эксплуатации подвижного состава. Ученый предложил объединить эти специальности в одну «инженер-механик по подвижному составу» [5].

В ходе индустриализации все более утверждалось представление об инженере как о субъекте, обслуживающим производство. Уже в 1941 году передовые педагоги понимали, что всему научить нельзя, необходимо научить студента методике организации расчетов с наименьшей затратой времени и с наибольшей надежностью получаемых результатов [2].

По мнению Б. Злобинского, заместителя начальника Наркомата черной металлургии, втузы должны выпускать инженеров, хорошо подготовленных не только теоретически, но и практически. Для этого надо тщательно продумывать организацию производственной практики студентов. Основная цель производственной практики, с точки зрения Б. Злобинского - научить студента глубоко разбираться в техническом процессе и приучить его к осознанному участию в нем. Для этого необходимо включать студентов в сменные бригады и подчиняться трудовому режиму предприятия [6].

Поднимается вопрос о качестве конструкторской подготовки инженеров. Конструкторская подготовка наилучшим образом формирует навык самостоятельной творческой работы, умение выделить и решить главное. Повышение качества конструкторской подготовки способствует повышению качества инженерной подготовки в целом. Фундаментом конструкторской подготовки являются общеинженерные дисциплины. Однако в этот период преподавание общеинженерных дисциплин сводится к формальному усвоению математических зависимостей, в то же время не рассматривается физический смысл и связь явлений. Отмечается 
недостаточное количество лабораторных работ, их формальное проведение [1, 12].

Однако, дальнейшие события мировой истории заставили отложить решение вопроса об улучшении качества подготовки инженерно-технических специалистов. В первые же дни Великой отечественной войны происходит перестройка работы высших технический учебных заведений применительно к потребностям военного времени. В соответствии со специальным планом, утвержденным Наркомом обороны, ведущим принципом в подготовке инженеров учить тому, что необходимо на войне. [6] Таким образом, характерными чертами в деятельности технических учебных заведений были:

- конкретность и целеустремленность;

- практическая направленность обучения;

- обеспечение единства воспитания и обучения. [12]

Проведенный ретроспективный анализ становления инженерного образования в России в период между революцией 1917 года до начала Великой отечественной войны, позволяет сделать следующие выводы:

- цель, характер обучения и образования зависят от целей и задач, стоящих перед государством на данном этапе и государственной образовательной политики; поддержка инженерного образования со стороны государства стимулировала развитие, а реформирование из-за идеологических мотивов это развитие сдерживало;

- для увеличения количества квалифицированных специалистов создана достаточно эффективная система массовой инженерной подготовки, в которой большое внимание уделялось практическим навыкам будущих инженеров;

- подготовка высококвалифицированных инженерных кадров в вузах неотделима от качественного школьного образования по естественным дисциплинам (математике, физике, химии);

- профессия инженера в России была престижной, инженеры гордились своим социальным статусом. 


\section{Список литературы}

1. Арефьев А.Л., Арефьев М.А. Инженерно-техническое образование в России в цифрах // Высшее образование в России. 2012. №3. С. $122-131$.

2. Виноградов Г.В. Вооружить студентов втузов знанием номографии // Вестник высшей школы. 1941. № 7.

3. Галкин К.Т. Высшее образование и подготовка научных кадров СССР. М.: Советская наука. 1921. 178 с.

4. Горохов В.Г. Техника и культура: возникновение философии техники и теории технического творчества в России и Германии в конце XIX - начале XX столетия. М.: Логос, 2010, 376 c.

5. Грицевский М.Е. Против излишнего дробления специальностей // Вестник высшей школы. 1941. №7.

6. Злобинский Б. Улучшить подготовку инженеров. // Вестник высшей школы. 1941. № 9.

7. Лебедев В. Соцдоговор // Инженерный труд. 1934. №3.

8. Ленинизм и техника // Инженерный труд. 1934. №1.

9. Морозов В.В., Николаенко В.И. История инженерной деятельности. Харьков, 2007. 336 с.

10. Талызина Н.Ф., Печенок Н.Г., Хохловский Л.Б. Пути разработки профиля специалиста. Саратов: Сарат. ун-т. 1987. 174 с.

11. Тарасова В.Н. Высшая инженерная школа России (последняя четверть XVIII в. - 1917 г.: диссертация на соискание ученой степени доктора исторических наук, Москва, 2000. 563 с.

12. Trofimova L.N. Maths training in terms of engineering education in Russia (historical aspect) // $2^{\text {nd }}$ International Academic Conference on Applied and Fundamental Studies. Vol. 2. March 8-10, 2013, St. Louis, Missouri, USA. 284 p.

\section{References}

1. Arefiev A.L., Arefiev M.A. Vysshee obrazovanie v Rossii [Higher education in Russia]. 2012. No. 3. P. 122-131.

2. Vinogradov G.V. Vestnik vysshey shkoly [Bulletin of the higher school]. 1941. No. 7. 
3. Galkin K.T. Vysshee obrazovanie i podgotovka nauchnykh kadrov SSSR [Higher education and training of scientific personnel of the USSR]. M.: Soviet science, $1921.178 \mathrm{p}$.

4. Gorokhov V.G. Tekhnika i kul tura: vozniknovenie filosofii tekhniki i teorii tekhnicheskogo tvorchestva $v$ Rossii i Germanii v kontse XIX-nachale $X X$ stoletiya [Technology and culture: the emergence of the philosophy of technology and the theory of technical creativity in Russia and Germany in the late XIX - early XX century]. M.: Logos, 2010, 376 p.

5. Gritsevsky M.E. Vestnik vysshey shkoly [Bulletin of the higher school]. 1941. No. 7.

6. Zlobinsky B. Vestnik vysshey shkoly [Bulletin of the higher school]. 1941. No. 9.

7. Lebedev V. Inzhenernyy trud [Engineering work]. 1934. No. 3.

8. Leninizm i tekhnika [Leninism and technology]. Inzhenernyy trud [Engineering work]. 1934. No. 1.

9. Morozov V.V., Nikolaenko V.I. Istoriya inzhenernoy deyatel'nosti [Engineering history]. Kharkov, 2007. 336 p.

10. Talyzina N.F., Pechenok N.G., Khokhlovskiy L.B. Puti razrabotki profilya spetsialista [Ways of developing a specialist's profile]. Saratov: Sarat. un-t. 1987.174 p.

11. Tarasova V.N. Vysshaya inzhenernaya shkola Rossii (poslednyaya chetvert'XVIII v. - 1917 [Higher Engineering School of Russia (last quarter of the 18th century - 1917]. Moscow, 2000. 563 p.

12. Trofimova L.N. Maths training in terms of engineering education in Russia (historical aspect). 2nd International Academic Conference on Applied and Fundamental Studies. Vol. 2. March 8-10, 2013, St. Louis, Missouri, USA. 284 p.

\section{ДАННЫЕ ОБ АВТОРАХ}

Ерошенко Александра Викторовна, доцент, кандидат технических наук, доцент

Федеральное государственное бюджетное образовательное учреждение высшего образования «Омский государственный университет путей сообщения» 
пр. К. Маркса, 35, г. Омск, Омская обл., 644046, Российская Федерачия

avx_firka@mail.ru

Трофимова Людмила Николаевна, доцент, кандидат педагогических наук, доцент

Федеральное государственное бюджетное образовательное учреждение высшего образования «Омский государственный университет путей сообщения»

пр. К. Маркса, 35, г. Омск, Омская обл., 644046, Российская Федерация

lytro@yandex.ru

\section{DATA ABOUT THE AUTHORS}

Eroshenko Alexandra Viktorovna, Associate Professor, Candidate of Technical Sciences (Ph. D.)

Omsk State Transport University

35, K. Marksa pr., Omsk, 644046, Russian Federation

avx_firka@mail.ru

SPIN-code: 5015-5688

ORCID: 0000-0002-3511-5209

Trofimova Ljudmila Nikolaevna, Associate Professor, Candidate of Pedagogical sciences (Ph. D.)

Omsk State Transport University

35, K. Marksa pr., Omsk, 644046, Russian Federation

lytro@yandex.ru

SPIN-code: 8019-6420

ORCID: 0000-0001-9968-6863 